\title{
The Effects of Bioactive Compounds from Blueberry and Blackcurrant Powder on Oat Bran Pastes: Enhancing In Vitro Antioxidant Activity and Reducing Reactive Oxygen Species in Lipopolysaccharide-Stimulated Raw264.7 Macrophages
}

\author{
Xiao Dan Hui ${ }^{1,2,3,+}$, Gang Wu ${ }^{1,3,+} \mathbb{D}$, Duo Han ${ }^{2}$, Xi Gong ${ }^{1,3}$, Xi Yang Wu ${ }^{2}$, Shu Ze Tang ${ }^{2}$, Margaret A. Brennan ${ }^{1}$ \\ and Charles S. Brennan 1,3,4,*iD \\ check for \\ updates \\ 1 Department of Wine, Food and Molecular Biosciences, Faculty of Agriculture \& Life Sciences, \\ Lincoln University, Christchurch 7647, New Zealand; xiaodan.hui@lincolnuni.ac.nz (X.D.H.); \\ gang.wu@lincolnuni.ac.nz (G.W.); xi.gong@lincolnuni.ac.nz (X.G.); margaret.brennan@lincoln.ac.nz (M.A.B.) \\ 2 Department of Food Science and Engineering, Jinan University, Guangzhou 510632, China; \\ handuo@stu2018.jnu.edu.cn (D.H.); tkentwu@jnu.edu.cn (X.Y.W.); tangsz@jnu.edu.cn (S.Z.T.) \\ 3 Riddet Institute, Palmerston North 4442, New Zealand \\ 4 School of Science, RMIT University, 124 La Trobe Street, Melbourne, VIC 3000, Australia \\ * Correspondence: Charles.Brennan@lincoln.ac.nz; Tel./Fax: +64-34-230-637 \\ + The authors have made equal contributions and share the first authorship.
}

Citation: Hui, X.D.; Wu, G.; Han, D.; Gong, X.; Wu, X.Y.; Tang, S.Z.; Brennan, M.A.; Brennan, C.S. The Effects of Bioactive Compounds from Blueberry and Blackcurrant Powder on Oat Bran Pastes: Enhancing In Vitro Antioxidant Activity and Reducing Reactive Oxygen Species in Lipopolysaccharide-Stimulated Raw264.7 Macrophages. Antioxidants 2021, 10, 388. https://doi.org/ 10.3390/antiox10030388

Academic Editors: Dimitrios Kouretas and Fabio Galvano

Received: 27 January 2021

Accepted: 1 March 2021

Published: 5 March 2021

Publisher's Note: MDPI stays neutral with regard to jurisdictional claims in published maps and institutional affiliations.

Copyright: (c) 2021 by the authors. Licensee MDPI, Basel, Switzerland. This article is an open access article distributed under the terms and conditions of the Creative Commons Attribution (CC BY) license (https:// creativecommons.org/licenses/by/ $4.0 /)$.

\begin{abstract}
In this study, blueberry and blackcurrant powder were chosen as the phenolic-rich enrichments for oat bran. A Rapid Visco Analyser was used to form blueberry and blackcurrant enriched oat pastes. An in vitro digestion process evaluated the changes of phenolic compounds and the in vitro antioxidant potential of extracts of pastes. The anthocyanidin profiles in the extracts were characterised by the $\mathrm{pH}$ differential method. The results showed that blueberry and blackcurrant powder significantly increased the content of phenolic compounds and the in vitro antioxidant capacity of pastes, while the total flavonoid content decreased after digestion compared to the undigested samples. Strong correlations between these bioactive compounds and antioxidant values were observed. Lipopolysaccharide-stimulated RAW264.7 macrophages were used to investigate the intracellular antioxidant activity of the extracts from the digested oat bran paste with $25 \%$ enrichment of blueberry or blackcurrant powder. The results indicated that the extracts of digested pastes prevented the macrophages from experiencing lipopolysaccharide (LPS)-stimulated intracellular reactive oxygen species accumulation, mainly by the Kelch-like ECH-associated protein 1 (Keap1)/nuclear factor erythroid 2-related factor 2 (Nrf2) signalling pathway. These findings suggest that the bioactive ingredients from blueberry and blackcurrant powder enhanced the in vitro and intracellular antioxidant capacity of oat bran pastes, and these enriched pastes have the potential to be utilised in the development of the functional foods.
\end{abstract}

Keywords: antioxidant; in vitro digestion; phenolic compounds; reactive oxygen species; macrophages

\section{Introduction}

Oxidative stress plays a central role in the initiation and progression of several chronic diseases, including obesity and diabetes. Oxidative stress can damage cellular structures along with the under-production of antioxidant mechanisms, leading to the progression of obese or diabetic-related complications [1,2]. The ensuing cellular damage, such as DNA cross-linking and apoptosis has been reported to be a result of oxidative stress, and it is a fundamental pathological process in a variety of chronic diseases [3]. These diseases have been shown to possess increased cellular levels of reactive oxygen species (ROS) and ROS-induced DNA damage [4]. The Kelch-like ECH-associated protein 1 (KEAP1)/nuclear factor erythroid 2-related factor 2 (Nrf2) stress response pathway is the principal inducible 
defence against oxidative stress [5]. This signalling pathway regulates the expression of more than 100 genes and functions related to oxidative stress and cell survival, including direct antioxidant proteins, electrophile detoxification enzymes, free radical metabolism, the recognition of DNA damage, and the inhibition of inflammation [6,7].

With the growing number of people being diagnosed with these metabolic syndromes, it is crucial to find a new solution. Epidemiological studies and randomised control trials [8] have shown that dietary modification (in particular whole fruit and grains intake) are protective against diabetes and obesity since the complex mixture of phytochemicals from these foods has additive and synergistic effects [9]. Therefore, the consumption of antioxidant molecules has been shown to be effective as a strategy to prevent, or reduce, the risk of these diseases.

Research [10] has indicated the benefits of natural antioxidants, such as polyphenols derived from natural plants, compared with synthetic antioxidants. However, the intensified accumulation, safe consumption, and toxic effects of these polyphenols should be considered [11]. Polyphenols have been studied in cell culture and animal studies for their protective role. Various coloured berries, especially blueberry and blackcurrantwidely distributed in New Zealand [12] — contain a large number of polyphenols, such as phenolic acids and flavonoids [13]. Anthocyanin is a major subclass of flavonoids [14]. The major anthocyanins identified in blueberries are 3-glycosidic derivatives of cyanidin, delphinidin, and malvidin, in which the most common derivatives detected are based on sugars, such as glucose [15]. The major anthocyanins in blackcurrant are delphinidin-3-Oglucoside, cyanidin-3-O-glucoside, and cyanidin-3-O-rutinoside [16,17]. These bioactive compounds have been found to protect cells from oxidative stress [18] and to improve the ability of plasma antioxidants, thus reducing the risk of different human chronic diseases, including obesity and type 2 diabetes $[19,20]$. This increase in plasma antioxidant capacity following the consumption of polyphenol-rich food may be responsible either for the presence of the metabolites of polyphenols in plasma, or for their preservative effects on other reducing agents, such as endogenous antioxidants, or for their effect on the absorption of pro-oxidative food components, such as iron [21].

A whole grain oat diet has been credited in conferring health-promoting benefits. Oat bran is particularly high in antioxidants compared to other parts of the oat grain [22]. Recent studies have also shown that the health benefits of oats are mainly due to the antioxidants found in the bran-in addition to the phenolic compounds, such as potent avenanthramides, which are a family of antioxidants unique to oats [23]. Avenanthramides are substituted $\mathrm{N}$-cinnamoyl anthranilic acids, consisting of anthranilic acid and cinnamic acid moieties. These bioactive compounds in oat bran have been demonstrated to have the potential to reduce inflammation, possess anticancer properties, and lower blood sugar levels [24]. A concentrated extract of oat bran can be used as a natural antioxidant for foods, protecting the long-chain fatty acids from oxidative stress and from creating off-flavours in foods, since oat bran is a good source of antioxidants [25].

Consumer's interest in naturally coloured foods is growing. Free-flowing dried fruit powder can be easily incorporated into foods in a mixed form. Dehydrated fruit powders, such as blueberry and blackcurrant, can be mixed with oatmeal to prepare breakfast cereals $[20,26,27]$. A study of Schmidt, et al. [28] revealed that dried wild blueberry powder did not decrease the in vitro anti-proliferation activity in comparison to that of the fresh fruit. However, few studies have reported the use of combinations of berry fruits with oat bran, and no studies have focused on the potential synergistic effect on the food matrix of combining berries and oat bran. Therefore, in this study, blueberry powder and blackcurrant powder were chosen as the phenolic-rich enrichments for the oat bran. An in vitro digestion process was performed to observe the food matrix effects on the changes in their phenolic contents and in vitro antioxidant potential. The $\mathrm{pH}$ differential method was conducted to identify the major anthocyanidins in blueberry and blackcurrant enriched pastes. Furthermore, lipopolysaccharide-stimulated RAW264.7 macrophages were employed to investigate the intracellular antioxidant activity of the extracts from 
blueberry and blackcurrant enriched pastes. The potential mechanisms of this intracellular activity elicited by the extracts were also studied.

\section{Materials and Methods}

\subsection{Chemicals and Materials}

Blueberry powder and blackcurrant powder were purchased online (Viberi, Timaru, New Zealand). Oat bran was obtained from the local supermarket (Sun Valley, Christchurch, New Zealand). Pepsin (EC 3.4.23.1) pancreatin (EC 232-468-9), $\alpha$-amyloglucosidase (EC 3.2.1.3), invertase (EC 3.2.1.26), 2,2'-Azino-bis (3-ethylbenzothiazoline-6-sulfonic acid) diammonium salt (ABTS), 2,4,6-Tris(2-pyridyl)-s-triazine (TPTZ), 2-Diphenyl-1-picrylhydrazyl (DPPH), 3,5Dinitrosalicylic acid (DNS, 98\%, ACROS Organics ${ }^{\mathrm{TM}}$, Waltham, MA, USA ), Folin and Ciocalteu's phenol reagent, 2,7 dichlorodihydrofluorescein-diacetate (DCFH-DA), gallic acid, rutin, and trolox (6-hydroxy-2,5,7,8-tetramethylchroman-2-carboxylic acid) were all purchased from Sigma-Aldrich (St. Louis, MO, USA). Other chemicals in this study were of analytical grade.

\subsection{Preparation of the Pastes}

Oat bran (OB), blueberry (BB) powder and blackcurrant $(\mathrm{BC})$ powder were the raw materials used for the preparation of food matrices. Pastes were made using a Rapid Visco Analyser (RVA-Super 4, Perten instruments, Sydney Australia) [29]. The equations (1) and (2) were used to determine the weight of water and raw materials. OB $(5.28 \mathrm{~g}, 2.34 \%$, moisture basis) supplemented with $0,10,15$, and $25 \%(\mathrm{w} / \mathrm{w}) \mathrm{BB}$ powder or BC powder was prepared to develop the pastes. The slurry was heated from 50 to $95^{\circ} \mathrm{C}$ at a rate of $6{ }^{\circ} \mathrm{C} / \mathrm{min}$, held at $95^{\circ} \mathrm{C}$ for $5 \mathrm{~min}$, then cooled at a rate of $6{ }^{\circ} \mathrm{C} / \mathrm{min}$ to $50{ }^{\circ} \mathrm{C}$, and finally held at $50^{\circ} \mathrm{C}$ for $2 \mathrm{~min}$. The spindle speed was kept at $160 \mathrm{rpm}$, except for the first $10 \mathrm{~s}$ where it was increased to $960 \mathrm{rpm}$ to disperse the mixture. The pastes were coded as OBP (nothing added, control group); $\mathrm{ABB}_{10}, \mathrm{ABB}_{15}$, and $\mathrm{ABB}_{25}$ (oat bran paste enriched with $10 \%, 15 \%$, and $25 \% \mathrm{BB}$ powder, respectively), and $\mathrm{ABC}_{10}, \mathrm{ABC}_{15}$, and $\mathrm{ABC}_{25}$ (oat bran paste enriched with $10 \%, 15 \%$, and $25 \% \mathrm{BC}$ powder, respectively). All the pastes were stored at $4{ }^{\circ} \mathrm{C}$ overnight.

Equivalent sample and water mass can be calculated using the following formulas [30]. This is normalised for the moisture of the oat flour at 14\% (gives a factor of 86 in the equation):

$$
\begin{gathered}
S=\frac{86 \times 6.0}{100-M} \\
W=25+(6.0-S)
\end{gathered}
$$

where $S=$ corrected sample weight $(\mathrm{g}), W=$ corrected water weight $(\mathrm{g})$ and $M=$ actual moisture content of sample (in \%).

\subsection{Extraction of Phenolics from Raw Materials and Pastes}

All the pastes were freeze dried at -30 to $-40{ }^{\circ} \mathrm{C}$ using pilot scale lyophilization system (Millrock Technology, Inc., Kingston, NY, USA) for 72 h, and then the lyophilised samples were put in vacuum-incubators, and stored at $4{ }^{\circ} \mathrm{C}$. Afterwards, the extraction procedure was performed with two solvent systems [31]: acidic methanol/water (50:50 $\mathrm{v} / \mathrm{v}$, $\mathrm{pH}=2)$ and acetone/water $(70: 30 v / v, \mathrm{pH}=2)$, respectively, followed with the step of vortexing, sonication, centrifugation and evaporation. The final extracts were stored at $-80^{\circ} \mathrm{C}$.

\subsection{Simulation of the In Vitro Digestion}

The in vitro digestion method was modified according to a previous study [32]. The entire procedure was performed in a $37^{\circ} \mathrm{C}$ incubator with constant shaking table at $120 \mathrm{r} / \mathrm{min}$. A total of $2 \mathrm{~g}$ of each lyophilised sample was mixed well with $30 \mathrm{~mL}$ of distilled water for $10 \mathrm{~min}$, and then the $\mathrm{pH}$ value of the mixture was adjusted to 2.0 with $6 \mathrm{~N} \mathrm{HCl}$. Pepsin was added at a concentration of $0.05 \mathrm{~g} / \mathrm{mL}$ of the sample, and the mixture was incubated for $1 \mathrm{~h}$. After finishing the gastric digestion, a $1 \mathrm{~mL}$ of aliquot from each sample was taken (time 0 ) 
and added to $4 \mathrm{~mL}$ of absolute ethanol to stop further reactions. The $\mathrm{pH}$ of the digest was adjusted to 6.0 by the dropwise addition of $0.9 \mathrm{M} \mathrm{NaHCO}_{3}$. After the $\mathrm{pH}$ adjustment, $0.1 \mathrm{~mL}$ of $\alpha$-amyloglucosidase $(3000 \mathrm{U} / \mathrm{mL})$ was added. The digestion time began as soon as $5 \mathrm{~mL}$ of pancreatin-bile solution $(3 \mathrm{~g} / \mathrm{mL}$ pancreatin and $0.025 \mathrm{~g} / \mathrm{mL}$ bile salts in $0.1 \mathrm{M}$ $\mathrm{NaHCO}_{3}, \mathrm{pH}=7.4$ ) was added. After incubating for $120 \mathrm{~min}$, aliquots from the digesta of each sample were individually treated with ethanol and centrifuged at $2500 \mathrm{~g}$ for $20 \mathrm{~min}$. The supernatants were collected. The digested samples were extracted, followed by the extraction procedure in Section 2.3, and then filtered through $0.22 \mu \mathrm{m}$ Millipore filters and stored at $-80^{\circ} \mathrm{C}$ for further analysis.

\subsection{Determination of the Total Phenol Content (TPC)}

The total phenol content (TPC) of the extracts from undigested and digested samples was measured as described by Kim and Lee [33], with some modifications. A total of $0.5 \mathrm{~mL}$ of each sample was placed in tubes and $2.5 \mathrm{~mL}$ of $0.2 \mathrm{~N}$ Folin-Ciocalteu reagent and $2.0 \mathrm{~mL}$ of $7.5 \% \mathrm{Na}_{2} \mathrm{CO}_{3}$ were added to each tube. These tubes were mixed well and incubated in a water bath at $40{ }^{\circ} \mathrm{C}$ for $30 \mathrm{~min}$. Once the mixture was cooled to room temperature, the absorbance was measured at $760 \mathrm{~nm}$ by a spectrophotometer. Gallic acid was used as a standard to determine TPC of the extract and digesta as mg gallic acid equivalent (GAE)/g sample.

\subsection{Determination of the Total Flavonoid Content (TFC)}

Total flavonoid content (TFC) was measured using aluminium chloride reagent [34] A total of $250 \mu \mathrm{L}$ of each sample was mixed with $75 \mu \mathrm{L}$ of sodium nitrite solution $(5 \%, w / v)$, followed by $150 \mu \mathrm{L}$ of aluminium chloride $(10 \%, w / v), 500 \mu \mathrm{L}$ of sodium hydroxide $(1 \mathrm{~mol} / \mathrm{L})$, and finally, $775 \mu \mathrm{L}$ of distilled water. The mixture was shaken and incubated at room temperature for $30 \mathrm{~min}$. The absorbance of the mixture was measured at $415 \mathrm{~nm}$. Results are expressed as mg rutin equivalents (RE)/g sample.

\subsection{Determination of the Total Monomeric Anthocyanins Content (TMAC)}

Total monomeric anthocyanins content (TMAC) was determined by the $\mathrm{pH}$ differential method [35]. Extracts were diluted separately with $0.025 \mathrm{~mol} / \mathrm{L}$ hydrochloric acidpotassium chloride buffer $(\mathrm{pH}=1)$ and $0.4 \mathrm{~mol} / \mathrm{L}$ sodium acetate buffer $(\mathrm{pH}=4.5)$. These dilutions were allowed to balance for $15 \mathrm{~min}$. The absorbance of the mixture was measured at $530 \mathrm{~nm}$ and $700 \mathrm{~nm}$, respectively, using a UV-Vis spectrophotometer (UV1800, Shimadzu, Kyoto, Japan). The absorbance of the diluted sample was calculated according to the equation:

$$
A=\left(A_{530 \mathrm{~nm}}-A_{700 \mathrm{~nm}}\right)_{\mathrm{pH} 1.0}-\left(A_{530 \mathrm{~nm}}-A_{700 \mathrm{~nm}}\right)_{\mathrm{pH} 4.5}
$$

The TMAC was expressed as mg cyanidin-3-glucoside equivalents (Cy-3GE)/g sample as in the equation:

$$
\text { Anthocyanidin pigment }(\mathrm{mg} / \mathrm{L})=\frac{A \times M W \times D F \times V \times 1000}{\varepsilon \times l \times m}
$$

where $A$ is the absorbance, $M W$ is the molecular weight of cyanidin-3-glucoside $(449.2 \mathrm{~g} / \mathrm{mol})$, $D F$ is the dilution factor, $V$ is the solvent volume $(\mathrm{mL}), \varepsilon$ is the molar absorptivity $\left(26,900 \mathrm{~L} \cdot \mathrm{mol}^{-1} \cdot \mathrm{cm}^{-1}\right)[36], l$ is the cell path length $(1 \mathrm{~cm})$ and $m$ is the sample weight.

\subsection{In Vitro Antioxidant Activity Assay}

\subsubsection{DPPH Assay}

The radical scavenging capacity of the extract was determined by the DPPH assay, as described by Floegel et al. [37]. A total of $1 \mathrm{~mL}$ of freshly prepared $0.1 \mathrm{mM}$ methanolic DPPH solution was added into $0.5 \mathrm{~mL}$ of the extract, or digesta, and incubated for $30 \mathrm{~min}$ in the dark. The absorbance of the reaction mixture was measured at $517 \mathrm{~nm}$. Trolox was 
used as standard and the DPPH radical scavenging capacity was expressed as $\mu$ moL trolox equivalent (TE)/g sample.

\subsubsection{ABTS Assay}

The ABTS assay was adapted from a previous study [37]. The ABTS ${ }^{+}$cation radical solution was produced by reacting $9.5 \mathrm{~mL}$ of $7 \mathrm{mM}$ ABTS stock solution and $245 \mu \mathrm{L}$ of $100 \mathrm{mM} \mathrm{K} \mathrm{S}_{2} \mathrm{O}_{8}$ solution and incubating this solution in the dark at room temperature for $16 \mathrm{~h}$ before use. The ABTS ${ }^{++}$radical cation solution was diluted with $\mathrm{PBS}(\mathrm{pH}=7.4)$ to an absorbance of $0.70 \pm 0.02$ at $734 \mathrm{~nm}$. The diluted ABTS ${ }^{++}$radical cation solution $(3 \mathrm{~mL})$ was thoroughly mixed with $0.3 \mathrm{~mL}$ extract or digesta. The mixture was kept in the dark for $6 \mathrm{~min}$ at room temperature. Absorbance values were measured at $734 \mathrm{~nm}$. Trolox was used as the standard. Results are expressed as $\mu \mathrm{moL}$ trolox equivalent (TE)/g sample.

\subsubsection{FRAP Assay}

The reducing ability and antioxidant power activity of each extract was determined using a Ferric Reducing Antioxidant Power (FRAP) reagent solution [38]. The fresh FRAP reagent solution was prepared with $300 \mu \mathrm{mol} / \mathrm{L}$ acetate buffer $(\mathrm{pH}=3.6), 10 \mathrm{mmol} / \mathrm{L}$ TPTZ (dissolved in $40 \mathrm{mmol} / \mathrm{L} \mathrm{HCl}$ ) and $20 \mathrm{mM} \mathrm{FeCl}_{3}$ at a ratio of 10:1:1 (v/v/v). A total of $2.5 \mathrm{~mL}$ of FRAP reagent solution was thoroughly mixed with $250 \mu \mathrm{L}$ extract. The mixture was incubated in the dark for $2 \mathrm{~h}$ at $37^{\circ} \mathrm{C}$ and the absorbance was measured at $593 \mathrm{~nm}$. $\mathrm{FeSO}_{4}$ solution was used as the standard. Results are expressed as $\mu \mathrm{moL} \mathrm{Fe}{ }^{3+}$ equivalent $\left(\mathrm{Fe}^{3+} \mathrm{E}\right) / \mathrm{g}$ sample.

\subsection{Cell Culture}

The RAW264.7 macrophage was purchased from the Cell Bank of the Shanghai Institute of Cell Biology and Biochemistry, Chinese Academy of Sciences (Shanghai, China). The cells were maintained in DMEM containing $100 \mathrm{U} / \mathrm{mL}$ penicillin, $100 \mu \mathrm{g} / \mathrm{mL}$ streptomycin, $2 \mathrm{mmol} / \mathrm{L}$ glutamine, and $10 \%$ fetal bovine serum. The cell was cultured at $37^{\circ} \mathrm{C}$ a humidified atmosphere of $5 \% \mathrm{CO}_{2}$.

\subsection{Determination of Cell Viability}

The intestinal digested extracts of $\mathrm{OBP}, \mathrm{ABB}_{25}$, and $\mathrm{ABC}_{25}$ were selected to study the effects of bioactive compounds from the extracts of pastes on the intracellular antioxidant activity of RAW264.7 macrophages. RAW264.7 macrophages were treated with digested extracts $\left(\mathrm{OBP}, \mathrm{ABB}_{25}\right.$, and $\left.\mathrm{ABC}_{25}\right)$ individually and plated at a density of $3.0 \times 10^{4}$ cells $/$ well in 96-well culture plates for $48 \mathrm{~h}$. Cell viability was determined using a Cell Counting Kit-8 (CCK-8) assay kit (Dalian Meilun Biotechnology Co., Ltd., Dalian, China) according to the instructions of the manufacturer. Absorbance was calculated for all samples at $450 \mathrm{~nm}\left(\mathrm{OD}_{450}\right)$. The relative cell viability was presented after normalised to untreated cells (control). Cell viability rates were measured after $24 \mathrm{~h}$ and were calculated based on $\mathrm{OD}_{450}$ values. Cell viability rate $(\%)=\mathrm{OD}_{450}$ (test) $/ \mathrm{OD}_{450}$ (control) $\times 100 \%$.

\subsection{Induction of Intracellular ROS Generation}

The intracellular changes in ROS generation were detected by staining the cells with 2,7 dichlorodihydrofluorescein-diacetate (DCFH-DA) [39]. RAW264.7 macrophages were seeded at a density of $4.0 \times 10^{5}$ cells/well in a 12-well culture plate, and were treated with extracts of $\mathrm{OBP}, \mathrm{ABB}_{25}$, and $\mathrm{ABC}_{25}(100$ and $200 \mu \mathrm{g} / \mathrm{mL})$ for $24 \mathrm{~h}$, and then $10 \mu \mathrm{L}$ of lipopolysaccharide (LPS, $250 \mathrm{ng} / \mathrm{mL}$ ) was added followed by $30 \mathrm{~min}$ incubattion. The cells were harvested and washed twice with cold PBS, then, cells were further incubated with $10 \mu \mathrm{M}$ DCFH-DA at $37^{\circ} \mathrm{C}$ for $30 \mathrm{~min}$. Subsequently, the cells were washed two times using PBS. Prior to ROS measurement, $100 \mu \mathrm{L}$ of PBS was added to each well. ROS generation was assessed by flow cytometry. 


\subsection{Luciferase Reporter Nrf2 Gene Assay}

RAW264.7 cells were seeded at a density of $2 \times 10^{5}$ cells/well in a 24-well plate in serum free DMEM (did not contain antibiotics), and incubated at $37^{\circ} \mathrm{C}$ for $5 \mathrm{~h}$. Cells were then transfected with Nrf2 using lipofectamine 2000 transfection reagent (invitrogen) and

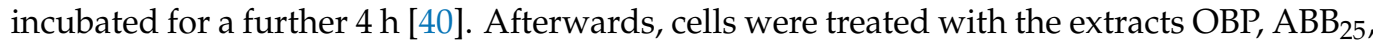
and $\mathrm{ABC}_{25}(100$ and $200 \mu \mathrm{g} / \mathrm{mL})$ for $24 \mathrm{~h}$, and then $10 \mu \mathrm{L}$ of LPS $(250 \mathrm{ng} / \mathrm{mL})$ was added to incubate for $30 \mathrm{~min}$. Luciferase activities were measured using Dual-Glo luciferase assay kit (Promega, Southampton, UK) according to the manufacturer's instructions.

\subsection{Western Blotting Assay}

After treatments with extracts individually for $24 \mathrm{~h}$, the cells were harvested, collected as cell pellets, and lysed in RIPA cell lysis buffer on ice for $1 \mathrm{~h}$. Protein concentrations were determined using a BCA Protein Assay Kit (Thermo, MA, USA). Equal proteins from each treatment were separated on a $10 \%$ SDS denaturing polyacrylamide gel and electrophoretically (SDS-PAGE) transferred to PVDF membranes. After blocking with 5\% non-fat milk, the membranes were incubated with primary antibodies (1:1000; Cell Signalling Technology) overnight at $4{ }^{\circ} \mathrm{C}$. Specific primary antibodies against Keap1, Nrf2, HO1 and $\beta$-actin were purchased from Beyotime (Shanghai, China). After washing thrice (10 $\mathrm{min}$ for each) with TBS solution, the PVDF membranes were incubated with corresponding secondary antibodies (Jackson ImmunoResearch Laboratories, West Grove, USA) for $1 \mathrm{~h}$. The blots were washed thrice (10 $\mathrm{min}$ for each) with TBS solution. Signals were detected by using an Enhanced Chemiluminescence (ECL) detection (Thermo, MA, USA) and Image J (Bethesda, MD, USA) software were used to quantify the blot density [40].

\subsection{Statistical Analysis}

The results are presented as the mean value \pm standard deviation. Unless stated elsewhere, experiments were performed in triplicate. One-way analysis of variance (ANOVA) was carried out. Pearson's correlation was conducted by using GraphPad Prism software version 8.0 (GraphPad Software, Inc., San Diego, CA, USA).

\section{Results}

\subsection{Changes in TPC and TFC during In Vitro Digestion}

Table 1 shows the TPC in extracts of raw materials and pastes at different digestion phases. Overall, although there was a decline in the TPC content of both raw materials and pastes after intestinal digestion, compared with the TPC after gastric digestion, the polyphenol concentration of each digested sample was higher than that of the corresponding undigested sample $(p<0.01$ or $p<0.05)$. Before digestion, BC powder yielded the highest TPC value of $97.15 \mathrm{mg}$ GAE/g, followed by BB powder $(84.91 \mathrm{mg} \mathrm{GAE} / \mathrm{g})$, while OBP showed the lowest TPC value of $0.43 \mathrm{mg}$ GAE/g. All of the BC-enriched pastes had higher TPC values than those of the BB-enriched pastes. The difference became more evident as the level of $\mathrm{BB}$ or $\mathrm{BC}$ powder increased in the pastes. The TPC in the extract of undigested $\mathrm{ABC}_{25}$ was 10-fold higher than that of undigested $\mathrm{ABB}_{25}$ and the ratio reduced to 2.4-fold after the intestinal digestion. Thus, $\mathrm{ABC}_{25}$ had the highest TPC value among all pastes $(p<0.01)$.

The TFC of the samples illustrated that BB powder displayed the highest TFC across the whole digestion, while OB had the lowest TFC value. The TFC value of all samples firstly increased after the gastric digestion, then decreased after the intestinal digestion. In OB, the TFC value after the intestinal digestion was so low that it could not be detected. BB-enriched pastes exhibited higher levels of TFC than those of BC-enriched pastes. For instance, before digestion, the TFC value of $\mathrm{ABB}_{25}$ was $45.12 \%$ higher than that of $\mathrm{ABC}_{25}$ $(p<0.01)$. After intestinal digestion, the TFC of $\mathrm{ABB}_{25}$ was $30 \%$ lower than the corresponding undigested sample, although it was still $9.4 \%$ higher than that of the intestinal digested extracts of $\mathrm{ABC}_{25}(p<0.01)$. The TFC trend of $\mathrm{BB}$ powder $>\mathrm{BC}$ powder $>$ BB-enriched 
pastes $>$ BC-enriched pastes $>$ OB $>$ OBP was maintained for TFC throughout the whole digestion process.

Table 1. The total phenol content (TPC) and total flavonoid content (TFC) of raw materials and pastes.

\begin{tabular}{|c|c|c|c|c|c|c|}
\hline \multirow{2}{*}{ Group } & \multicolumn{3}{|c|}{ In Vitro Digestion Phase } & \multicolumn{3}{|c|}{ Total Variation } \\
\hline & Extraction & Gastric & Intestinal & Samples (A) & Digestion Phase (B) & $A^{*} B$ \\
\hline Raw material & & & & $6.83 \%(p<0.001)$ & $86.10 \%(p<0.001)$ & $7.03 \%(p<0.001)$ \\
\hline OB & $1.49 \pm 0.01 \mathrm{Cc}$ & $5.02 \pm 0.02 \mathrm{Ac}$ & $2.26 \pm 0.04^{\mathrm{Bc}}$ & & & \\
\hline $\mathrm{BB}$ & $84.91 \pm 2.63^{\mathrm{Cb}}$ & $103.17 \pm 1.15^{\mathrm{Ab}}$ & $91.23 \pm 0.54^{\mathrm{Bb}}$ & & & \\
\hline $\mathrm{BC}$ & $97.15 \pm 5.31 \mathrm{Ca}$ & $186.70 \pm 0.23^{\mathrm{Aa}}$ & $122.78 \pm 0.67 \mathrm{Ba}$ & & & \\
\hline Paste & & & & $28.50 \%(p<0.001)$ & $65.20 \%(p<0.001)$ & $6.14 \%(p<0.001)$ \\
\hline OBP & $0.43 \pm 0.01^{\mathrm{Cm}}$ & $4.26 \pm 0.00 \mathrm{Am}$ & $2.25 \pm 0.09^{B n}$ & & & \\
\hline $\mathrm{ABB}_{10}$ & $0.53 \pm 0.07 \mathrm{Cm}$ & $5.22 \pm 0.14^{\mathrm{Al}}$ & $3.53 \pm 0.05^{\mathrm{Bm}}$ & & & \\
\hline $\mathrm{ABB}_{15}$ & $0.74 \pm 0.06^{\mathrm{Cl}}$ & $5.24 \pm 0.14 \mathrm{Al}$ & $3.92 \pm 0.02 \mathrm{Bl}$ & & & \\
\hline $\mathrm{ABB}_{25}$ & $1.60 \pm 0.06^{\mathrm{Ck}}$ & $6.21 \pm 0.23 \mathrm{Ak}$ & $4.98 \pm 0.09^{\mathrm{Bk}}$ & & & \\
\hline $\mathrm{ABC}_{10}$ & $2.93 \pm 0.17^{\mathrm{Cj}}$ & $14.08 \pm 0.65^{\mathrm{Aj}}$ & $7.52 \pm 0.27^{B j}$ & & & \\
\hline $\mathrm{ABC}_{15}$ & $5.85 \pm 0.18^{\mathrm{Ci}}$ & $15.89 \pm 0.40^{\mathrm{Ai}}$ & $10.44 \pm 0.31^{\mathrm{Bi}}$ & & & \\
\hline \multirow[t]{3}{*}{$\mathrm{ABC}_{25}$} & $10.82 \pm 0.36^{\mathrm{Ch}}$ & $18.06 \pm 0.19^{\mathrm{Ah}}$ & $11.96 \pm 0.08^{\mathrm{Bh}}$ & & & \\
\hline & \multicolumn{3}{|c|}{ In Vitro Digestion Phase } & \multicolumn{3}{|c|}{ Total Variation } \\
\hline & Extraction & Gastric & Intestinal & Samples (A) & Digestion Phase (B) & $A^{*} B$ \\
\hline Raw material & & & & $18.20 \%(p<0.001)$ & $74.70 \%(p<0.001)$ & $6.80 \%(p<0.001)$ \\
\hline OB & $2.82 \pm 0.42^{\mathrm{Bc}}$ & $4.77 \pm 0.51^{\mathrm{Ac}}$ & ND & & & \\
\hline BB & $48.25 \pm 2.31 \mathrm{Ba}$ & $65.48 \pm 1.23^{\mathrm{Aa}}$ & $27.77 \pm 2.39 \mathrm{Ca}$ & & & \\
\hline $\mathrm{BC}$ & $36.51 \pm 0.93^{\mathrm{Bb}}$ & $43.32 \pm 1.22 \mathrm{Ab}$ & $18.84 \pm 1.40^{\mathrm{Cb}}$ & & & \\
\hline Paste & & & & $32.30 \%(p<0.001)$ & $52.50 \%(p<0.001)$ & $13.50 \%(p<0.001)$ \\
\hline OBP & $0.96 \pm 0.07^{\mathrm{Bm}}$ & $2.00 \pm 0.19$ An & ND & & & \\
\hline $\mathrm{ABB}_{10}$ & $5.82 \pm 0.39 \mathrm{Bk}$ & $10.07 \pm 0.47^{\mathrm{Al}}$ & $2.13 \pm 0.09 \mathrm{Cl}$ & & & \\
\hline $\mathrm{ABB}_{15}$ & $11.17 \pm 0.90^{\mathrm{Bi}}$ & $21.27 \pm 0.87^{\mathrm{Aj}}$ & $5.26 \pm 0.06^{\mathrm{Cj}}$ & & & \\
\hline $\mathrm{ABB}_{25}$ & $24.51 \pm 6.15^{\mathrm{Bh}}$ & $37.62 \pm 2.71^{\mathrm{Ah}}$ & $7.66 \pm 0.19^{C h}$ & & & \\
\hline $\mathrm{ABC}_{10}$ & $2.46 \pm 0.10^{\mathrm{Bl}}$ & $7.95 \pm 0.08 \mathrm{Am}$ & $1.55 \pm 0.26^{\mathrm{Cm}}$ & & & \\
\hline $\mathrm{ABC}_{15}$ & $7.29 \pm 0.76^{\mathrm{Bj}}$ & $17.04 \pm 0.44^{\mathrm{Ak}}$ & $3.10 \pm 0.50^{C k}$ & & & \\
\hline $\mathrm{ABC}_{25}$ & $16.89 \pm 2.07^{\mathrm{Bh}}$ & $27.95 \pm 0.61^{\mathrm{Ai}}$ & $6.94 \pm 0.08^{\mathrm{Ci}}$ & & & \\
\hline
\end{tabular}

Mean \pm SD are presented $(n=3)$. Raw materials and pastes were compared separately. Comparison within the same raw material is expressed by uppercase letters, while comparison within the same column is expressed by lowercase letters. Values with different letters, per sample, are statistically different $(p<0.05)$. Abbreviations: TPC $=$ total phenolic content; $\mathrm{TFC}=$ total flavonoid content; $\mathrm{OB}=\mathrm{oat}$ bran; $\mathrm{BB}=$ blueberry powder; $\mathrm{BC}=$ blackcurrant powder; $\mathrm{OBP}=$ pure oat bran paste; $\mathrm{ABB}_{10}, \mathrm{ABB}_{15}$ and $\mathrm{ABB}_{25}=$ oat bran paste enriched with 10 , 15 and $25 \%$ blueberry powder, respectively; $\mathrm{ABC}_{10}, \mathrm{ABC}_{15}$ and $\mathrm{ABC}_{25}=$ oat bran paste enriched with 10,15 and $25 \%$ blackcurrant powder, respectively. All values are based on dry basis.

Research has illustrated the instability of TPC in a simulated digestion [41]. Herein, Both raw materials and pastes displayed increased TPC after the gastric phase, which subsequently declined after the intestinal phase, albeit above the undigested levels. Cebeci and Şahin-Yeşilçubuk [42] reported that combinations with milk generally resulted in a decrease in TPC and TFC as well as inhibition of antioxidant activities when evaluating the matrix effect of blueberry, oatmeal and milk on their polyphenols and antioxidant activities after in vitro digestion. This discrepancy might be related to differences in the food matrix characteristics and the in vitro conditions of the digestion. However, Sengul, Surek and Nilufer-Erdil [32] observed a higher recovery of TPC after the gastric digestion of the fruit extract. This finding was possibly due to an increase in flavylium cations in the acidic solution during the gastric phase of digestion, which is in agreement with results from this study. Therefore, it can be assumed that the increased values of TPC and TFC during the gastric phase are due to the acidic hydrolysis of phenolic glycosides to their aglycones. Furthermore, the decline in TFC values, subsequently resulted in the decreased TPC values in the intestinal phase. This is attributed to the degradation of phenolic compounds in the weak alkaline environment $(\mathrm{pH}=7.4)$, particularly flavonoids, which are highly sensitive to alkaline conditions. According to the study from Fawole and Opara [43] the decrease in phenolic compounds-notably anthocyanins in the intestinal phase of the in vitro digestion - was attributed to the transformation of the flavylium cation to the colourless chalcone when the digestion medium became alkaline. 
Changes in TPC and TFC of the extracts were influenced by the combined effects of dietary supplements and the phases of in vitro digestion, and the effects were considered extremely significant $(p<0.01)$. Crucially, these results show that the changes in TPC in extracts from raw materials and pastes were not constant throughout the in vitro digestion procedure. According to the percentage of total variation, for TPC and TFC, the digestion phase accounted for the most significant variation, indicating that the digestion process most likely contributes to the release of bioactive compounds due to the actions of the digestive enzymes, temperature, and $\mathrm{pH}$ conditions [44].

\subsection{The Changes in TMAC of the Extracts during In Vitro Digestion}

The anthocyanin pigment experiences a reversible structural transformation with changes of the $\mathrm{pH}$ value, and these changes are reflected in the absorption spectrum. Thus, the $\mathrm{pH}$ differential method could measure the values rapidly and accurately, even when the degraded polymerised pigments and other interfering compounds were present [15]. Table 2 illustrates the changes in the TMAC values in the extracts of raw materials and pastes during in vitro digestion. Amongst the extracts from undigested samples, the extract of $B C$ powder had the highest TMAC (36.27 mg Cy-3GE/100 g), followed by the extract of BB powder (14.96 mg Cy-3GE/100 g). TMAC in the OB extract was low, $0.03 \mathrm{mg} C y-$ $3 \mathrm{GE} / 100 \mathrm{~g}$. In terms of the extracts from pastes, the TMAC in the extract of OBP was too low to be detected. TMAC in the extracts of BB- and BC-enriched pastes varied from 0.25 to $0.66 \mathrm{mg}$ Cy-3GE $/ 100 \mathrm{~g}$. The extract of BC-enriched paste was given more TMAC compared to the corresponding extract of BB-enriched paste $(p<0.01)$. TMAC in all extracts decreased after undergoing in vitro digestion. TMAC in the extracts of $B B$ and $B C$ powder decreased by over $95 \%$ compared to the corresponding undigested extracts $(p<0.01)$. TMAC in the $\mathrm{OB}$ extract could not be detected in both the gastric and intestinal phase. Even though the TMAC in the extracts from the pastes experienced a decrease after in vitro digestion, $\mathrm{BC}$-enriched pastes still exhibited higher TMAC values compared with the corresponding $\mathrm{BB}-\mathrm{enriched}$ pastes. Among these extracts from intestinal digested pastes, $\mathrm{ABC}_{25}$ had the highest TMAC value $(0.35 \mathrm{mg}$ Cy-3GE $/ 100 \mathrm{~g})(p<0.01)$.

Table 2. The changes in TMAC values of the extracts during in vitro digestion ( $\mathrm{mg} / 100 \mathrm{~g}$ sample).

\begin{tabular}{|c|c|c|c|}
\hline \multicolumn{4}{|c|}{ TMAC (mg Cy-3GE/100 g Sample) } \\
\hline \multirow{2}{*}{ Group } & \multicolumn{3}{|c|}{ In Vitro Digestion Phase } \\
\hline & Extraction & Gastric & Intestinal \\
\hline \multicolumn{4}{|l|}{ Raw material } \\
\hline Oat bran & $0.03 \pm 0.01 \mathrm{Ac}$ & $\mathrm{ND}$ & ND \\
\hline Blueberry powder & $14.96 \pm 1.48^{\mathrm{Ab}}$ & $0.99 \pm 0.03^{\mathrm{Bb}}$ & $0.62 \pm 0.02 \mathrm{Cb}$ \\
\hline $\begin{array}{c}\text { Blackcurrant powder } \\
\text { Paste }\end{array}$ & $36.27 \pm 1.69$ Аа & $3.90 \pm 0.03 \mathrm{Ba}$ & $3.43 \pm 0.04 \mathrm{Ca}$ \\
\hline $\mathrm{OBP}$ & ND & ND & ND \\
\hline $\mathrm{ABB}_{10}$ & $0.25 \pm 0.02 \mathrm{Al}$ & $0.11 \pm 0.02 \mathrm{Bk}$ & ND \\
\hline $\mathrm{ABB}_{15}$ & $0.30 \pm 0.01 \mathrm{Ak}$ & $0.13 \pm 0.02 \mathrm{Bk}$ & $0.04 \pm 0.01 \mathrm{Ck}$ \\
\hline $\mathrm{ABB}_{25}$ & $0.41 \pm 0.00^{\mathrm{Aj}}$ & $0.16 \pm 0.02 \mathrm{Bj}$ & $0.08 \pm 0.00 \mathrm{Cj}$ \\
\hline $\mathrm{ABC}_{10}$ & $0.40 \pm 0.01 \mathrm{Ai}$ & $0.18 \pm 0.03 \mathrm{Bj}$ & $0.12 \pm 0.01 \mathrm{Ci}$ \\
\hline $\mathrm{ABC}_{15}$ & $0.64 \pm 0.00^{\mathrm{Ah}}$ & $0.40 \pm 0.03^{\mathrm{Bi}}$ & $0.13 \pm 0.02 \mathrm{Ci}$ \\
\hline $\mathrm{ABC}_{25}$ & $0.66 \pm 0.03^{\mathrm{Ah}}$ & $0.62 \pm 0.02 \mathrm{Bh}$ & $0.35 \pm 0.01 \mathrm{Ch}$ \\
\hline
\end{tabular}

Values are mean \pm standard deviation, $n=3$. Raw materials and pastes were compared separately. Values with different uppercase letters, in the same row, are statistically different $(p<0.05)$, while values with different lowercase letters, in the same column are statistically different $(p<0.05)$. TMAC $=$ total monomeric anthocyanins content; $\mathrm{OBP}=$ pure oat bran paste; $\mathrm{ABB}_{10}, \mathrm{ABB}_{15}$ and $\mathrm{ABB}_{25}=$ oat bran paste enriched with 10,15 and $25 \%$ blueberry powder, respectively; $A B C_{10}, A_{B C}$ and $A_{15} C_{25}=$ oat bran paste enriched with 10,15 and $25 \%$ blackcurrant powder, respectively; $\mathrm{ND}=$ no data. All values are based on the dry basis. 
The instability of these extracts could be responsible for the change of the $\mathrm{pH}$ values during the digestion. As a food colorant, anthocyanin is very sensitive to a higher $\mathrm{pH}$ (alkaline conditions). Therefore, the decline in the TMAC values after the intestinal phase was less pronounced than the decrease after the gastric phase. In addition to the influence of $\mathrm{pH}$ values, the temperature may have had a significant effect on the degradation of anthocyanins. Refrigeration has been shown to be an effective means of preserving anthocyanins. Muche et al. [45] compared the amount of anthocyanidin content lost in blackcurrant juice stored at 4 and $37{ }^{\circ} \mathrm{C}$, observing that blackcurrant anthocyanidin contents lost $40 \%$ at $4{ }^{\circ} \mathrm{C}$, while no measurable amounts of blackcurrant anthocyanidin were found at $37^{\circ} \mathrm{C}$. The short-term high temperature treatment could improve the stability of anthocyanin by facilitating the inactivation of native enzymes that are harmful to anthocyanins. Herein, the decline in the TMAC in the extracts of the pastes was less than those in the extracts of raw materials. This could because during the formation of the pastes, samples experienced a short-term high temperature procedure $\left(95^{\circ} \mathrm{C}\right.$ for $\left.10 \mathrm{~min}\right)$, which may have prevented anthocyanins from degrading to some extent [46].

In addition, the freeze-drying technique is widely used in high-quality food preparation, as this technique has been proven to be able to preserve the bioactive compounds effectively [47]. Therefore, in this study, all the pastes were treated with freeze-drying for $72 \mathrm{~h}$ to preserve the bioactive ingredients in these pastes.

\subsection{Changes in Antioxidant Activity during In Vitro Digestion}

The radical scavenging activity of the samples prior to digestion, as measured by scavenging DPPH and ABTS free radicals, reflected the same trend as the TPC levels in all samples, with BC powder $>$ BB powder $>$ BC-enriched pastes $>$ BB-enriched pastes $>\mathrm{OB}$ $>$ OBP (Figure 1a,b). After the gastric phase, the radical scavenging activity of both raw materials and pastes decreased, varying from a 13 to $33 \%$ reduction in the DPPH assay and from a 20 to $89 \%$ reduction in the ABTS assay $(p<0.01)$. The radical scavenging activity of all raw materials after the intestinal phase was lower than that of the corresponding undigested extracts. Both BB- and BC-enriched pastes seemed to be effective in scavenging the DPPH and $\mathrm{ABTS}^{+}$free radical, and contrary to the raw materials, the radical scavenging activity of these pastes was higher after the intestinal digestion compared to the radical scavenging activity exhibited by the undigested pastes $(p<0.01)$. The DPPH values of the intestinal digesta of BB- and BC-enriched pastes increased between 1- and 1.54-fold compared with the undigested extracts $(p<0.01)$. The same trend was observed for the ABTS assay results, with the scavenging values of intestinally digested BB- and BCenriched pastes being higher by 14 to $53 \%$, compared to the corresponding undigested pastes $(p<0.01)$.

The reducing antioxidant powers measured by FRAP of the raw materials and pastes were consistent with the TPC measured in the undigested paste (Figure 1c). Overall, $\mathrm{BC}$ powder showed the highest antioxidant power $\left(714 \mathrm{mmol} \mathrm{FeSO}_{4} / \mathrm{g}\right)$, followed by BB powder (282 $\left.\mathrm{mmol} \mathrm{FeSO}_{4} / \mathrm{g}\right)$. In terms of the pastes, OBP showed the lowest antioxidant power (13 mmol $\left.\mathrm{FeSO}_{4} / \mathrm{g}\right)$. With increasing levels of enrichments, the FRAP value of BBand $\mathrm{BC}$-enriched pastes increased, ranging between 0.9- and 6.2-fold compared with OBP $(p<0.01)$. BC-enriched pastes showed stronger reducing power than BB-enriched pastes. Interestingly, the FRAP values increased significantly at the gastric phase for all samples, perhaps as a result of the TPC at this phase. However, the reducing powers then generally decreased $(p<0.01)$ by 7 to $76 \%$ at the intestinal phase, with larger decreases observed in the raw materials values compared with those observed for the pastes. Although there was a decrease after the final phase, FRAP values after the intestinal digestion remained higher than the undigested extracts $(p<0.01)$.

The fluctuation of the reducing power, in all of the samples, could be due to the $\mathrm{pH}$ of the medium. The $\mathrm{pH}$ of a substance is known to influence molecule racemisation, possibly creating two chiral enantiomers with different reactivities. Therefore, some antioxidants could be more sensitive at acidic $\mathrm{pH}$ in the gastric phase and less reactive at alkaline $\mathrm{pH}$ 
in the intestinal phase. Bouayed, et al. [48] reported a similar trend of reducing powder in apple varieties. They found that the reducing antioxidant capacity present in apple varieties, as determined in methanolic extracts, was significantly higher compared to those found in gastric digesta for all apple varieties, while the reducing power present in the intestinal digesta of apple varieties was lower than those found in gastric digesta. Regarding the change in reduction of antioxidant power from the gastric phase to the intestinal phase, the phenolics responsible for ferric reduction may reduce or convert to certain metabolites with different chemical properties, as these polyphenols are highly sensitive to alkaline conditions [49].

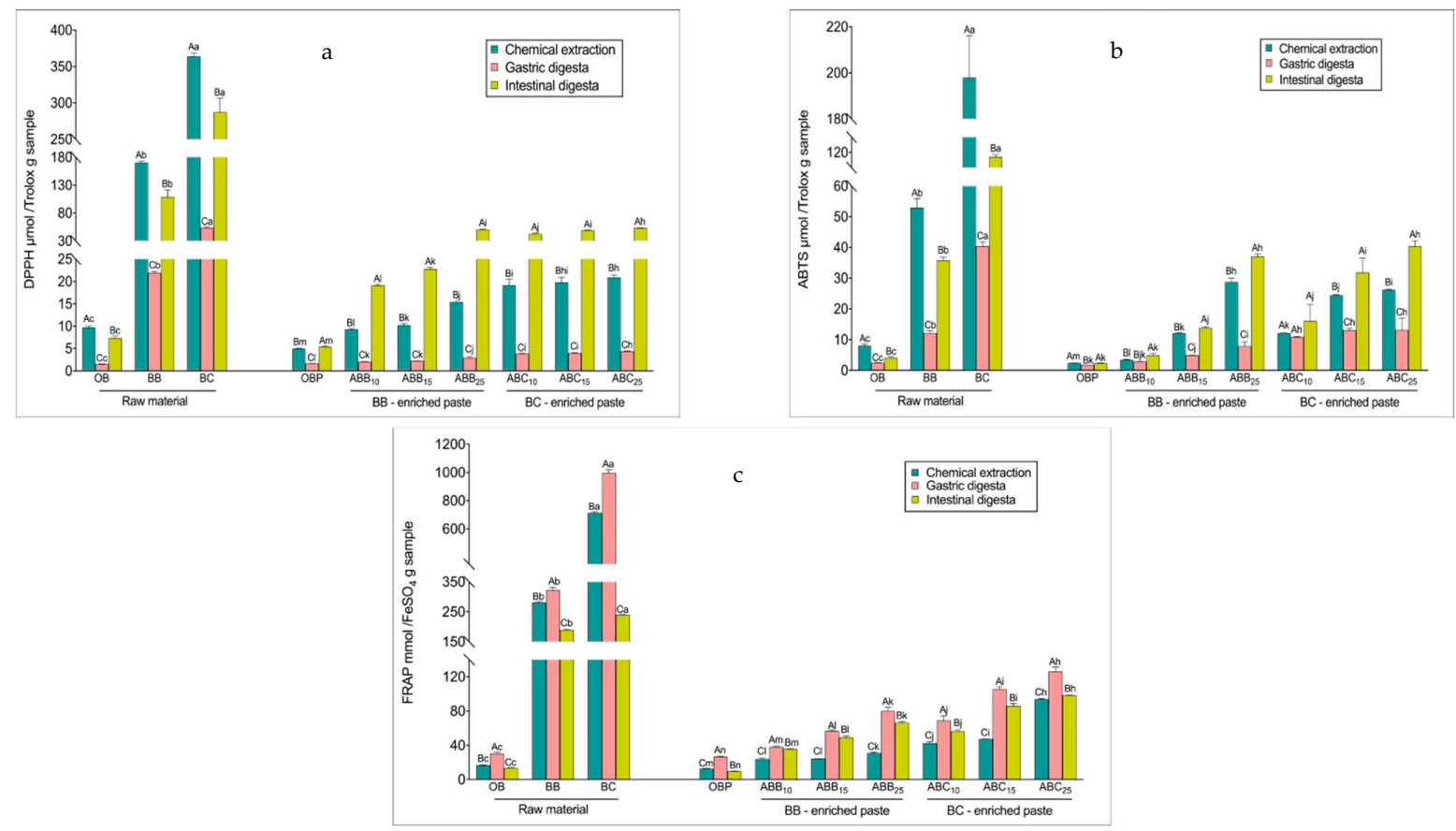

Figure 1. Changes in antioxidant activities during in vitro digestion. DPPH (2-Diphenyl-1-picrylhydrazyl) values (a), 2,2'-Azino-bis (3-ethylbenzothiazoline-6-sulfonic acid) diammonium salt (ABTS) values (b), and Ferric Reducing Antioxidant Power (FRAP) values (c), respectively. Values with different uppercase letters at different digestion phases in one sample are statistically different, while values of bars in the same colour with different lowercase letters are statistically different $(p<0.05)$. OBP = pure oat bran paste; $\mathrm{ABB}_{10}, \mathrm{ABB}_{15}$ and $\mathrm{ABB}_{25}=$ oat bran paste enriched with 10,15 and $25 \%$ blueberry powder, respectively; $\mathrm{ABC}_{10}, \mathrm{ABC}_{15}$ and $\mathrm{ABC}_{25}=$ oat bran paste enriched with 10,15 and $25 \%$ blackcurrant powder, respectively.

The DPPH and ABTS assays are based on the ability of antioxidants to scavenge the $\mathrm{DPPH}$ and $\mathrm{ABTS}^{++}$radicals activities. The DPPH and ABTS values of the pastes showed a different behaviour from the FRAP value, displaying a decline in the gastric phase, followed by an increase after the intestinal phase in relation to the gastric phase. The decline in DPPH and ABTS values in the gastric phase could be related to the degradation of anthocyanins responsible for the scavenging activities due to the acidic environment. The increased DPPH and ABTS values could be to the deprotonation of the hydroxyl groups present on the aromatic rings, facilitating the hydrogen donation reactions and decreasing the ionization potential, consequently increasing the electron donation capacity. In addition, the formation of new metabolites from anthocyanins that can become antioxidant radicals could lead to the increased DPPH and ABTS values.

Çelik, et al. [50] reported that once cereal products are consumed, a large proportion of insoluble antioxidants bound to dietary fibres reach the colon, without digestion occurring, and become bound to antioxidant radicals themselves. Meanwhile, soluble antioxidants regenerate bound antioxidant radicals, thereby prolonging their antioxidant action. Masisi et al. [51] also reported that after the consumption of breakfast cereals, an- 
tioxidant activities increased significantly after in vitro digestion compared to the chemical solvent extraction procedure used for undigested samples. These reports explain the increased reducing power of all blueberry and blackcurrant enriched pastes. Antioxidant activities of foods varies depending on the content of phenolic compounds, flavonoids, proteins, lipids and carbohydrates [52].

\subsection{Pearson's Correlations between Phenolic Compounds and Three Antioxidant Assays}

The correlation coefficients between TPC, TFC, and the anthocyanidin content (Table 3) and antioxidant activity values - analysed by the three assays — were recorded before and after in vitro digestion. Strong positive correlations were observed between these phenolic compounds and antioxidant activity values. The anthocyanidin content had stronger correlations with antioxidant activity values compared to TPC and TFC. As shown in Table 3, the correlation coefficients between the anthocyanin content and DPPH values were all larger than 0.97 in the undigested $\left(R^{2}=0.992, p<0.01\right)$, gastric digested $\left(R^{2}=0.982\right.$, $p<0.01)$, and digested samples $\left(\mathrm{R}^{2}=0.979, p<0.01\right)$, followed by the FRAP values, which had stronger correlations in the undigested and gastric digested samples $\left(R^{2}=0.996\right.$, $p<0.01$ ) when compared to the intestinal digested samples. In our previous study [53], four types of anthocyanidins, including delphinidin, cyanidin, petunidin, and malvidin, were identified in the extract of blueberry powder-enriched paste, while delphinidin and cyanidin were detected in the extract of blackcurrant powder-enriched paste. Therefore, these anthocyanidins could be responsible for the radical scavenging activity and reducing power in the sample extracts. However, the functionality of the food is not only dependent on the bioactive compounds in food system, but is also highly influenced by the other surrounding compounds, such as lipids, proteins and fibres. Therefore, the whole food matrix should be taken into consideration. In our previous study, the nutritional components in the raw materials and pastes, and the negative correlations were observed between antioxidant activity (DPPH, ABTS $^{+}$and FRAP) and nutritional components, including fat, protein and total starch content, while strong positive correlations were found between antioxidant activity and p-coumaric acid content and garlic acid content. Previously, metabolites formed as a result of structural changes brought about by the alkaline conditions have been shown to have a different reactivity in the FRAP assay [54]. However, some insoluble antioxidant compounds remaining in indigestible materials may be underestimated by the three assays [55].

Table 3. Pearson's correlation between phenolic compounds and three antioxidant assays values.

\begin{tabular}{|c|c|c|c|}
\hline & Before Digestion & Gastric & Intestinal \\
\hline \multicolumn{4}{|c|}{ Pearson's Correlation between TPC and Three Antioxidant Assays Values } \\
\hline DPPH values & $0.8708 * *$ & $0.9783 * *$ & $0.8641^{* *}$ \\
\hline ABTS values & $0.6867^{* *}$ & $0.7748 * *$ & $0.6941^{* *}$ \\
\hline FRAP values & $0.8449 * *$ & $0.9382 * *$ & $0.9279 * *$ \\
\hline \multicolumn{4}{|c|}{ Pearson's Correlation between TFC and Three Antioxidant Assays Values } \\
\hline DPPH values & $0.5724 *$ & 0.3737 & $0.4996 *$ \\
\hline ABTS values & 0.4333 * & 0.2707 & 0.4245 * \\
\hline FRAP values & $0.5080 *$ & 0.3279 & $0.7968^{* *}$ \\
\hline \multicolumn{4}{|c|}{ Pearson's Correlation between TMAC and Three Antioxidant Assays Values } \\
\hline DPPH values & $0.9922 * *$ & $0.9820 * *$ & $0.9790 * *$ \\
\hline ABTS values & $0.9551 * *$ & $0.9650 * *$ & $0.9188 * *$ \\
\hline FRAP values & $0.9951 * *$ & $0.9962 * *$ & $0.8376^{* *}$ \\
\hline
\end{tabular}

\subsection{The Extracts of BB-and BC-Enriched Pastes Reduced the Intracellular ROS Level in LPS-Stimulated RAW264.7}

A CCK-8 assay was performed to evaluate the effects of the extracts from intestinal digested blueberry and blackcurrant enriched pastes on RAW264.7 cell viability. As shown 
in Figure 2, the extracts of digested 25\% blueberry and 25\% blackcurrant enriched pastes exhibited stronger inhibitory activity against cell growth of RAW264.7, compared to the extract of digested OBP $(p<0.01)$. In order to make sure the cell viability was more than $90 \%$, the concentrations of 100 and $200 \mu \mathrm{g} / \mathrm{mL}$ extracts of digested pastes were chosen for subsequent analyses.

a

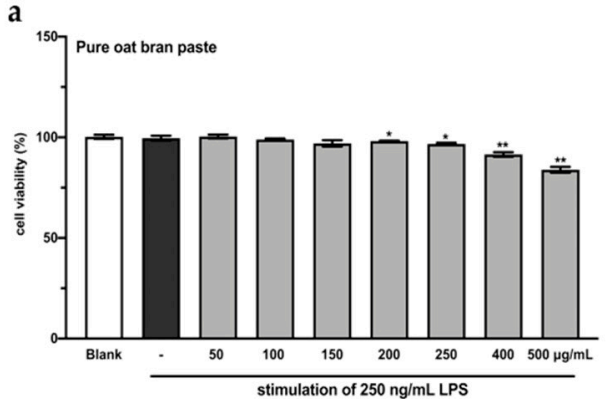

b
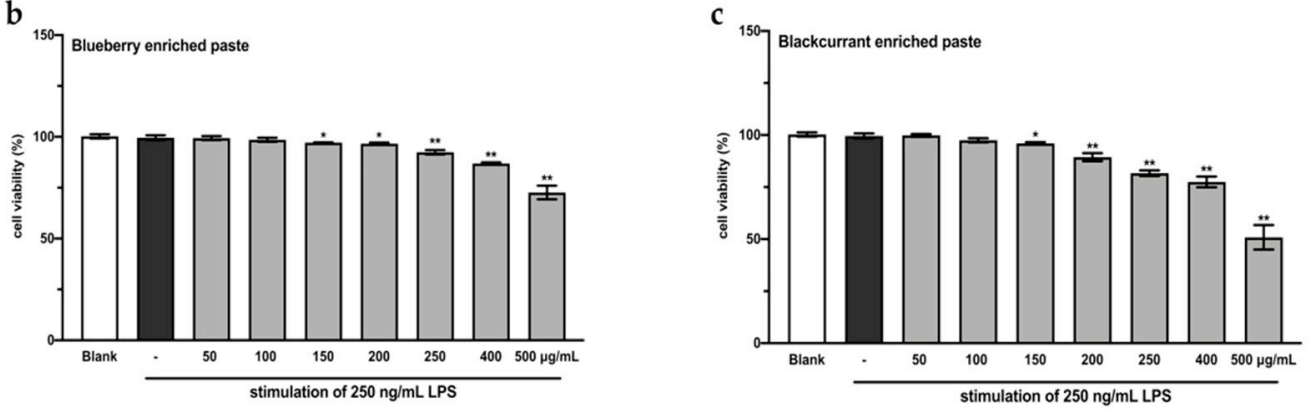

Figure 2. RAW264.7 cell viability after treating with varying concentrations of extracts from digested oat bran paste (a), 25\% blueberry-enriched paste (b), and 25\% blackcurrant-enriched paste (c) for $48 \mathrm{~h}$. The values represent the mean $\pm \mathrm{SD}$ of three independent experiments. ${ }^{*} p<0.05,{ }^{* *} p<0.01$ compared to the control group.

LPS-induced intracellular ROS accumulation was monitored within cells using a DCFH2-DA fluorescence microscopic analysis. As shown in Figure 3, the incubation of LPS-stimulated RAW264.7 cells with the extract of OBP (100 and $200 \mu \mathrm{g} / \mathrm{mL}$ ) showed no significant reduction in the intracellular ROS, while co-treatment with the extracts of BB- and BC-enriched pastes $(100$ and $200 \mu \mathrm{g} / \mathrm{mL})$ resulted in a considerable $(p<0.05)$ dose-dependent reduction in ROS accumulation in LPS-induced RAW264.7 cells. Among these, the $200 \mu \mathrm{g} / \mathrm{mL}$ extract of $\mathrm{ABC}_{25}$ exhibited the most significant reduction of ROS concentration, reducing the ROS level by approximately four-fold compared to the control group $(p<0.01)$. Therefore, it can be suggested that the enrichment of BB or BC powder for oat bran could suppress LPS-induced ROS generation in macrophages.

ROS are created by a variety of cellular processes as part of cellular signalling events. A number of studies have suggested that ROS participate in inflammation, and LPSinduced ROS generation has been widely reported in various in vitro and in vivo studies [56]. In particular, ROS are major oxidative products that are primarily released by the mitochondria, peroxisomes, and inflammatory cell activation by endotoxins in macrophages. Moreover, ROS production is an important component of the initiation and enhancement of cell death via apoptosis or autophagy [57]. In this study, stimulation of LPS enhanced intracellular ROS accumulation in RAW264.7 macrophages, and this elevated intracellular ROS accumulation was significantly inhibited by the extracts of BBand $\mathrm{BC}$-enriched pastes (bioactive compounds from BB and BC powder). 


\subsection{The Extracts of BB- and BC-Enriched Pastes Activated the Antioxidant Gene Nrf2 in LPS-Stimulated RAW264.7 via Keap1/Nrf2/HO-1 Signalling Pathway}

Nrf2 is a transcription factor that serves as a sensor for oxidative stress, and coordinates the expression of antioxidant stress response genes upon exposure to oxidative stimulation [58]. Herein, we hypothesised that the protective effects of the extracts of digested BB- and BC-enriched pastes against LPS-stimulated oxidative stress (intracellular ROS accumulation) were regulated by the induction of antioxidant genes through the Nrf2 gene. The results of the luciferase reporter gene assay (Figure 4) showed that the extracts of BB- and BC-enriched pastes (100 and $200 \mu \mathrm{g} / \mathrm{mL}$ ) significantly increased the expression of the Nrf2 gene compared to the extract of OBP $(p<0.05)$. Among these extracts, the extract of $200 \mu \mathrm{g} / \mathrm{mL} \mathrm{ABC}_{25}$ led to the most significant increase in the expression of the Nrf2 gene. This result is in agreement with the concentration of intracellular ROS accumulation in RAW264.7 macrophages. Collectively, these findings suggest that the bioactive compounds from $\mathrm{BB}$ and $\mathrm{BC}$ powder could promote the activation of the Nrf2 gene in macrophages.
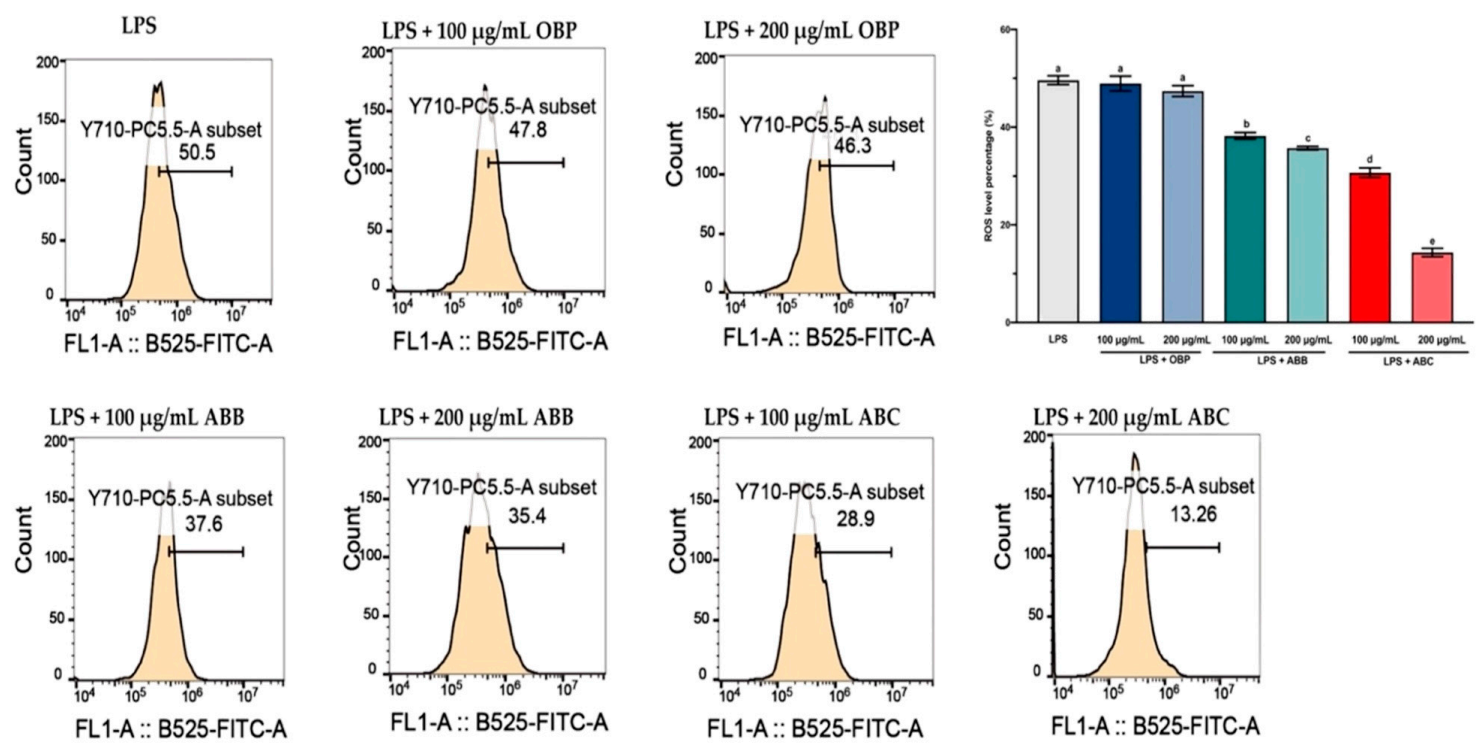

Figure 3. The reactive oxygen species (ROS) levels in LPS-stimulated RAW264.7 macrophages treated with or without the extracts of $\mathrm{OBP}, \mathrm{ABB}$, and $\mathrm{ABC}$. The values are represented by mean $\pm \mathrm{SD}$. Values with different letters indicate significant differences $(p<0.05, n=3)$. OBP $=$ pure oat bran paste; $\mathrm{ABB}=25 \%$ of blueberry powder enriched oat bran paste; $\mathrm{ABC}=25 \%$ of blackcurrant powder enriched oat bran paste.

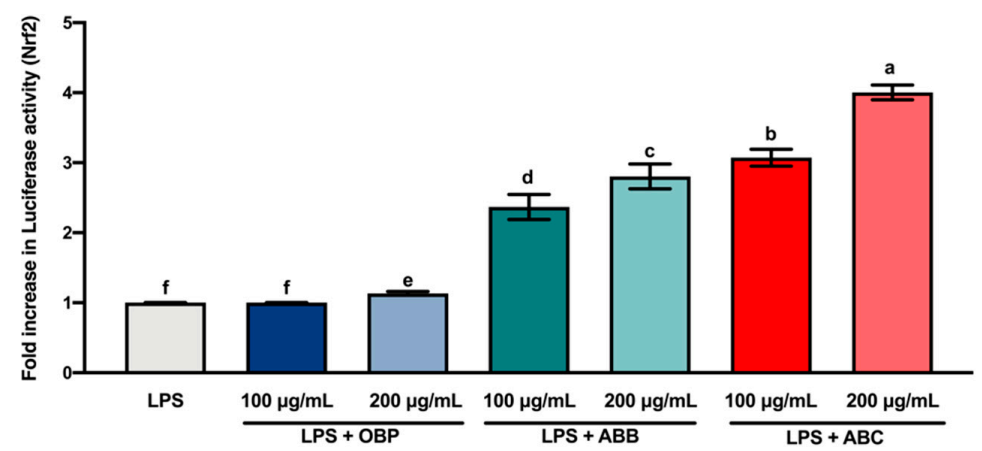

Figure 4. The Luciferase activity (Nrf2) of lipopolysaccharide (LPS)-stimulated RAW264.7 macrophages treated with or without the extracts of $\mathrm{OBP}, \mathrm{ABB}$, and $\mathrm{ABC}$. The values are represented by mean $\pm \mathrm{SD}$. Values with different letters indicate statistically significant differences $(p<0.05, n=3)$. $\mathrm{OBP}=$ pure oat bran paste; $\mathrm{ABB}=25 \%$ of blueberry powder enriched oat bran paste; $\mathrm{ABC}=25 \%$ of blackcurrant powder enriched oat bran paste. 
To further confirm this protective effect, the extracts of $\mathrm{ABB}_{25}(62.5,125$, and $250 \mu \mathrm{g} / \mathrm{mL})$ and $\mathrm{ABC}_{25}(50,100$, and $200 \mu \mathrm{g} / \mathrm{mL})$ were selected to perform a Western blotting assay to investigate the mechanism of the activation of the Nrf2 gene by the extracts. As shown in Figure 5, the extracts of $\mathrm{ABB}_{25}$ and $\mathrm{ABC}_{25}$ significantly activated the Nrf2 signalling pathway by down-regulation of the protein expressions of Keap1, and up-regulation of the protein expression of Nrf2 and its downstream factor heme oxygenase 1 (HO1) in a dose-dependent manner $(p<0.05)$.

a
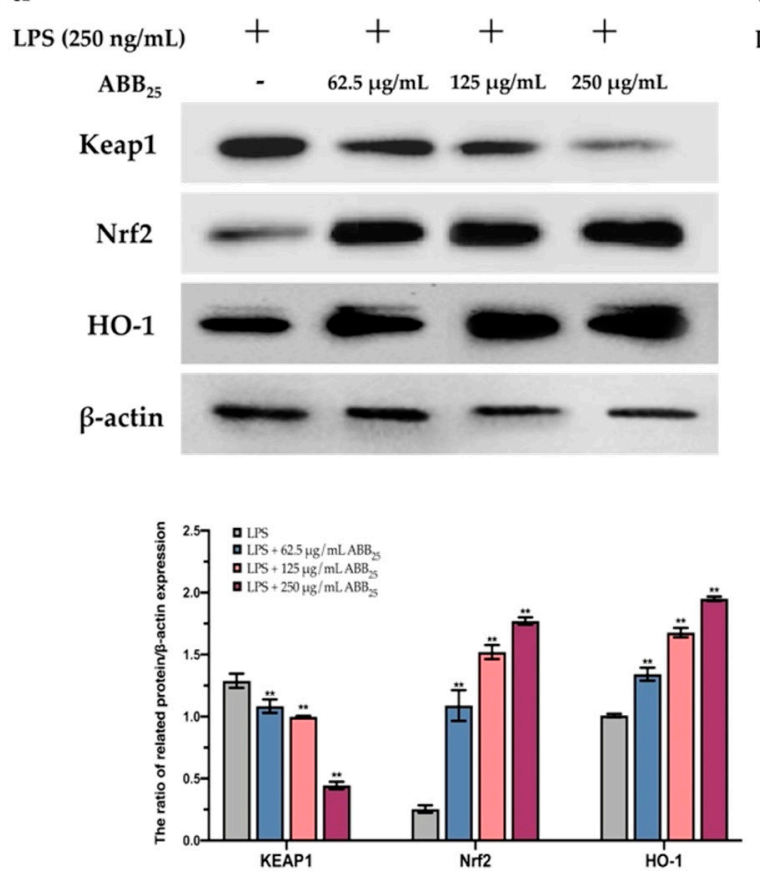

b
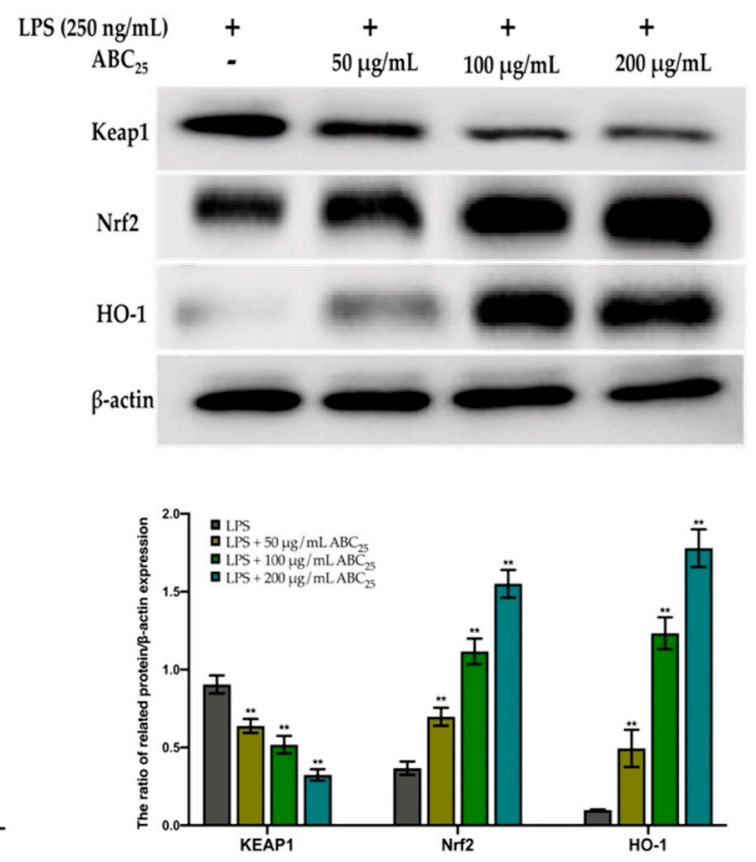

Figure 5. The protein expression of KEAP1, Nrf2, and HO-1 of LPS-stimulated RAW264.7 macrophages treated with or without the varying concentrations of the extracts of $\mathrm{ABB}_{25}(\mathbf{a})$ and $\mathrm{ABC}_{25}(\mathbf{b})$. The values are represented by mean $\pm \mathrm{SD}$, $\mathrm{n}=3$. Bars with ${ }^{* *}$ mean there is difference from lipopolysaccharide (LPS) group (** $p<0.01$ ). $\mathrm{ABB}_{25}=25 \%$ of blueberry powder enriched oat bran paste; $\mathrm{ABC}_{25}=25 \%$ of blackcurrant powder enriched oat bran paste.

The Keap1/Nrf2 pathway is the main cytoprotective regulator in responses to endogenous and exogenous stresses induced by ROS [59]. Transcription factor Nrf2, a key signalling protein within the pathway, binds with small Maf proteins to the antioxidant response element (ARE) in the regulatory regions of target genes. Keap 1 is a repressor protein that binds to Nrf2 and promotes its degradation via the ubiquitin proteasome pathway [60]. It has been documented that Keap1/Nfr2-mediated antioxidant genes are stimulated by various external stimuli and by plant-derived natural products [61]. Activated Nrf2 binds the DNA at ARE binding motifs to activate the transcription of various detoxifying enzymes, including HO-1 [62]. HO-1 is a well-known antioxidant enzyme which plays a major in the defence against LPS-stimulated ROS generation in macrophages. HO-1 expression has also been shown to be driven by Nrf2 [63]. These antioxidant enzymes are important in the prevention of cell carcinogenesis, and in the protection from oxidative stress and electrophile toxicity. The induction of these antioxidant genes has been assumed to be the mechanism through which Nrf2 inhibits LPS-stimulated inflammation [64]. A previous study [65] revealed that induction of antioxidant enzyme (HO-1) expression can reduce intracellular ROS levels, creating an improved intracellular environment, and maintaining Nrf2 in its augmented configuration. In this study, the expression of the Nrf2 gene in macrophages significantly increased in the presence of the extracts of $\mathrm{ABB}_{25}$ and $A B C_{25}$, suggesting that the elimination of intercellular ROS may be due to the activation of Nrf2 by the extracts. This is consistent with previous studies, revealing that the extracts of 
many plants contain anti-inflammatory agents inhibited the intracellular ROS accumulation through the activation of Nrf2 cascades in macrophages. These results demonstrate that the protective effect of the extracts is mediated primarily by Nrf2 activation. Thus, the bioactive compounds in the extracts protected the macrophages from LPS-stimulated intracellular ROS accumulation, mainly by elevating the intracellular anti-oxidative enzymes via enhancing the accumulation of Nrf2, and thus, dramatically inducing the expression of the antioxidant gene $\mathrm{HO}-1$, in response to LPS stimulation.

\section{Conclusions}

In conclusion, incorporation of 10,15 , and $25 \%$ of blackcurrant or blueberry powder with oat bran increased the content of bioactive compounds. The bioactive compounds from BB- and BC-enriched pastes mainly contributed to their in vitro antioxidant activities. Furthermore, the enrichment of $25 \%$ blueberry and $25 \%$ blackcurrant powder into oat bran was chosen to investigate the intracellular antioxidant activities in LPS-stimulated RAW264.7 macrophages. The results indicated that the extracts of intestinal digested $\mathrm{ABB}_{25}$ and $\mathrm{ABC}_{25}$ (bioactive compounds in the extracts) prevented the macrophages from experiencing LPS-stimulated intracellular ROS accumulation, mainly via the Keap1/Nrf2 signalling pathway, enhancing the accumulation of the Nrf2 gene and consequently inducing the expression of the antioxidant genes $\mathrm{HO}-1$, in response to LPS stimulation. In addition, after experiencing the digestion, the extract from the $25 \%$ blackcurrant powder enriched paste still exhibited stronger protective effects of in vitro and intracellular antioxidant activity than that of the $25 \%$ blueberry powder enriched paste. For future work, a combination of a cell line study with an in vivo study in a mouse model should be developed. We recommend this study focusses on the production of the metabolites of polyphenols that are dominant in the circulation. Taken together, the findings in this study signify the importance of the intake of polyphenol-rich cereal food products.

Author Contributions: Conceptualization, X.D.H., C.S.B. and G.W.; methodology, X.D.H. and D.H.; software, X.D.H.; validation, X.D.H., G.W. and X.G.; formal analysis, X.D.H.; investigation, X.D.H. and D.H.; resources, X.D.H.; data curation, G.W.; writing-original draft preparation, X.D.H.; writing-review and editing, X.D.H., G.W., X.G., X.Y.W., S.Z.T., M.A.B. and C.S.B.; visualization, X.D.H.; supervision, C.S.B.; project administration, C.S.B.; funding acquisition, X.Y.W., S.Z.T., M.A.B. and C.S.B. All authors have read and agreed to the published version of the manuscript.

Funding: This research received no external funding.

Institutional Review Board Statement: Not applicable.

Informed Consent Statement: Not applicable.

Data Availability Statement: The data presented in this study are available on request from the corresponding author.

Conflicts of Interest: The authors declare no conflict of interest.

\section{References}

1. Oguntibeju, O.O. Type 2 diabetes mellitus, oxidative stress and inflammation: Examining the links. Int. J. Physiol. Pathophysiol. Pharmacol. 2019, 11, 45-63. [PubMed]

2. Manna, P.; Jain, S.K. Obesity, Oxidative Stress, Adipose Tissue Dysfunction, and the Associated Health Risks: Causes and Therapeutic Strategies. Metab. Syndr. Relat. Disord. 2015, 13, 423-444. [CrossRef] [PubMed]

3. Uttara, B.; Singh, A.V.; Zamboni, P.; Mahajan, R.T. Oxidative stress and neurodegenerative diseases: A review of upstream and downstream antioxidant therapeutic options. Curr. Neuropharmacol. 2009, 7, 65-74. [CrossRef]

4. Nita, M.; Grzybowski, A. The Role of the Reactive Oxygen Species and Oxidative Stress in the Pathomechanism of the Age-Related Ocular Diseases and Other Pathologies of the Anterior and Posterior Eye Segments in Adults. Oxid. Med. Cell. Longev. 2016, 2016, 3164734. [CrossRef] [PubMed]

5. Roos, N.J.; Aliu, D.; Bouitbir, J.; Krähenbühl, S. Lapatinib Activates the Kelch-Like ECH-Associated Protein 1-Nuclear Factor Erythroid 2-Related Factor 2 Pathway in HepG2 Cells. Front. Pharmacol. 2020, 11, 944. [CrossRef] 
6. Cai, M.; Tong, L.; Dong, B.; Hou, W.; Shi, L.; Dong, H. Kelch-like ECH-associated Protein 1-dependent Nuclear Factor-E2related Factor 2 Activation in Relation to Antioxidation Induced by Sevoflurane Preconditioning. Anesthesiology 2017, 126, 507-521. [CrossRef]

7. Katarína, S.; Mikó, E.; Kovács, T.; Leguina-Ruzzi, A.; Sipos, A.; Bai, P. Nuclear Factor Erythroid 2-Related Factor 2 in Regulating Cancer Metabolism. Antioxid. Redox Signal. 2020, 33, 966-997.

8. Chabot, G.G.; Touil, Y.S.; Pham, M.H.; Dauzonne, D. Flavonoids in Cancer Prevention and Therapy: Chemistry, Pharmacology, Mechanisms of Action, and Perspectives for Cancer Drug Discovery. In Alternative and Complementary Therapies for Cancer; Springer: Boston, MA, USA, 2010; pp. 583-612.

9. Jurkiewicz-Przondziono, J.; Lemm, M.; Kwiatkowska-Pamuła, A.; Ziółko, E.; Wójtowicz, M.K. Influence of diet on the risk of developing endometriosis. Ginekol. Pol. 2017, 88, 96-102. [CrossRef]

10. Lourenço, S.C.; Moldão-Martins, M.; Alves, V.D. Antioxidants of Natural Plant Origins: From Sources to Food Industry Applications. Molecules 2019, 24, 4132. [CrossRef]

11. Gülçin, İ. Antioxidant activity of food constituents: An overview. Arch. Toxicol. 2012, 86, 345-391. [CrossRef]

12. Aboonabi, A.; Meyer, R.R.; Gaiz, A.; Singh, I. Anthocyanins in berries exhibited anti-atherogenicity and antiplatelet activities in a metabolic syndrome population. Nutr. Res. 2020, 76, 82-93. [CrossRef]

13. Wu, G.; Hui, X.; Gong, X.; Tran, K.N.; Stipkovits, L.; Mohan, M.S.; Brennan, M.A.; Brennan, C.S. Functionalization of bovine whey proteins by dietary phenolics from molecular-level fabrications and mixture-level combinations. Trends Food Sci. Technol. 2021, 110, 107-119. [CrossRef]

14. Olas, B. Berry Phenolic Antioxidants-Implications for Human Health? Front. Pharmacol. 2018, 9, 78. [CrossRef]

15. Khoo, H.E.; Azlan, A.; Tang, S.T.; Lim, S.M. Anthocyanidins and anthocyanins: Colored pigments as food, pharmaceutical ingredients, and the potential health benefits. Food Nutr. Res. 2017, 61, 1361779. [CrossRef]

16. Mazewski, C.; Kim, M.S.; Gonzalez de Mejia, E. Anthocyanins, delphinidin-3-O-glucoside and cyanidin-3-O-glucoside, inhibit immune checkpoints in human colorectal cancer cells in vitro and in silico. Sci. Rep. 2019, 9, 11560. [CrossRef] [PubMed]

17. Wu, G.; Hui, X.; Mu, J.; Brennan, M.A.; Brennan, C.S. Functionalization of whey protein isolate fortified with blackcurrant concentrate by spray-drying and freeze-drying strategies. Food Res. Int. 2021, 141, 110025. [CrossRef]

18. Abountiolas, M.; Do Nascimento Nunes, C. Polyphenols, ascorbic acid and antioxidant capacity of commercial nutritional drinks, fruit juices, smoothies and teas. Int. J. Food Sci. Technol. 2018, 53, 188-198. [CrossRef]

19. Cory, H.; Passarelli, S.; Szeto, J.; Tamez, M.; Mattei, J. The Role of Polyphenols in Human Health and Food Systems: A Mini-Review. Front. Nutr. 2018, 5, 87. [CrossRef] [PubMed]

20. Sun-Waterhouse, D. The development of fruit-based functional foods targeting the health and wellness market: A review. Int. J. Food Sci. Technol. 2011, 46, 899-920. [CrossRef]

21. Koch, W. Dietary Polyphenols-Important Non-Nutrients in the Prevention of Chronic Noncommunicable Diseases. A Systematic Review. Nutrients 2019, 11, 1039. [CrossRef]

22. Henrion, M.; Francey, C.; Lê, K.-A.; Lamothe, L. Cereal B-Glucans: The Impact of Processing and How It Affects Physiological Responses. Nutrients 2019, 11, 1729. [CrossRef]

23. Turrini, E.; Maffei, F.; Milelli, A.; Calcabrini, C.; Fimognari, C. Overview of the Anticancer Profile of Avenanthramides from Oat. Int. J. Mol. Sci. 2019, 20, 4536. [CrossRef]

24. Landberg, R.; Sunnerheim, K.; Dimberg, L.H. Avenanthramides as lipoxygenase inhibitors. Heliyon 2020,6 , e04304. [CrossRef] [PubMed]

25. Huang, D.; Ou, B.; Prior, R.L. The Chemistry behind Antioxidant Capacity Assays. J. Agric. Food Chem. 2005, 53, 1841-1856. [CrossRef] [PubMed]

26. Ma, L.; Sun, Z.; Zeng, Y.; Luo, M.; Yang, J. Molecular Mechanism and Health Role of Functional Ingredients in Blueberry for Chronic Disease in Human Beings. Int. J. Mol. Sci. 2018, 19, 2785. [CrossRef]

27. Camire, M.E.; Dougherty, M.P.; Briggs, J.L. Functionality of fruit powders in extruded corn breakfast cereals. Food Chem. 2007, 101, 765-770. [CrossRef]

28. Schmidt, B.M.; Erdman, J.W., Jr.; Lila, M.A. Effects of Food Processing on Blueberry Antiproliferation and Antioxidant Activity. J. Food Sci. 2005, 70, s389-s394. [CrossRef]

29. Balet, S.; Guelpa, A.; Fox, G.; Manley, M. Rapid Visco Analyser (RVA) as a Tool for Measuring Starch-Related Physiochemical Properties in Cereals: A Review. Food Anal. Methods 2019, 12, 2344-2360. [CrossRef]

30. AACC. Pasting Properties of Oat-Rapid Viscosity Analysis. AACC 11th Edition, Method 76-22.01. Available online: http://methods. aaccnet.org/summaries /76-22-01.aspx (accessed on 31 July 2009).

31. Annegowda, H.V.; Bhat, R.; Min-Tze, L.; Karim, A.A.; Mansor, S.M. Influence of sonication treatments and extraction solvents on the phenolics and antioxidants in star fruits. J. Food Sci. Technol. 2012, 49, 510-514. [CrossRef] [PubMed]

32. Sengul, H.; Surek, E.; Nilufer-Erdil, D. Investigating the effects of food matrix and food components on bioaccessibility of pomegranate (Punica granatum) phenolics and anthocyanins using an in-vitro gastrointestinal digestion model. Food Res. Int. 2014, 62, 1069-1079. [CrossRef]

33. Kim, J.-S.; Lee, Y.-S. Effect of reaction $\mathrm{pH}$ on enolization and racemization reactions of glucose and fructose on heating with amino acid enantiomers and formation of melanoidins as result of the Maillard reaction. Food Chem. 2008, 108, 582-592. [CrossRef] [PubMed] 
34. Zhou, L.; Lin, X.; Abbasi, A.M.; Zheng, B. Phytochemical Contents and Antioxidant and Antiproliferative Activities of Selected Black and White Sesame Seeds. BioMed Res. Int. 2016, 2016, 8495630. [CrossRef]

35. Lee, J.; Durst, R.W.; Wrolstad, R.E. Determination of Total Monomeric Anthocyanin Pigment Content of Fruit Juices, Beverages, Natural Colorants, and Wines by the pH Differential Method: Collaborative Study. J. AOAC Int. 2019, 88, 1269-1278. [CrossRef]

36. Liu, G.-L.; Guo, H.-H.; Sun, Y.-M. Optimization of the extraction of anthocyanins from the fruit skin of Rhodomyrtus tomentosa (Ait.) Hassk and identification of anthocyanins in the extract using High-Performance Liquid Chromatography-Electrospray Ionization-Mass Spectrometry (HPLC-ESI-MS). Int. J. Mol. Sci. 2012, 13, 6292-6302. [CrossRef] [PubMed]

37. Floegel, A.; Kim, D.-O.; Chung, S.-J.; Koo, S.I.; Chun, O.K. Comparison of ABTS/DPPH assays to measure antioxidant capacity in popular antioxidant-rich US foods. J. Food Compost. Anal. 2011, 24, 1043-1048. [CrossRef]

38. Sompong, R.; Siebenhandl-Ehn, S.; Linsberger-Martin, G.; Berghofer, E. Physicochemical and antioxidative properties of red and black rice varieties from Thailand, China and Sri Lanka. Food Chem. 2011, 124, 132-140. [CrossRef]

39. Choi, H.-S.; Seo, H.S.; Kim, S.R.; Choi, Y.K.; Shin, Y.-C.; Ko, S.-G. Anti-inflammatory and anti-proliferative effect of herbal medicines (APR) in RAW264.7 cells. Mol. Med. Rep. 2014, 9, 1569-1574. [CrossRef]

40. Yang, H.-L.; Lin, S.-W.; Lee, C.-C.; Lin, K.-Y.; Liao, C.-H.; Yang, T.-Y.; Wang, H.-M.; Huang, H.-C.; Wu, C.-R.; Hseu, Y.-C. Induction of Nrf2-mediated genes by Antrodia salmonea inhibits ROS generation and inflammatory effects in lipopolysaccharide-stimulated RAW264.7 macrophages. Food Funct. 2015, 6, 229-240. [CrossRef] [PubMed]

41. Mtolo, M.; Gerrano, A.; Mellem, J. Effect of simulated gastrointestinal digestion on the phenolic compound content and in vitro antioxidant capacity of processed Cowpea (V. unguiculata) cultivars. CyTA J. Food 2017, 15, 391-399. [CrossRef]

42. Cebeci, F.; Şahin-Yeşilçubuk, N. The matrix effect of blueberry, oatmeal and milk on polyphenols, antioxidant activity and potential bioavailability. Int. J. Food Sci. Nutr. 2014, 65, 69-78. [CrossRef]

43. Fawole, O.A.; Opara, U.L. Stability of total phenolic concentration and antioxidant capacity of extracts from pomegranate co-products subjected to in vitro digestion. BMC Complement. Altern. Med. 2016, 16, 358. [CrossRef]

44. Bhatt, A.; Patel, V. Antioxidant activity of garlic using conventional extraction and in vitro gastrointestinal digestion. Free Radic. Antioxid. 2013, 3, 30-34. [CrossRef]

45. Muche, B.M.; Speers, R.A.; Rupasinghe, H.P.V. Storage Temperature Impacts on Anthocyanins Degradation, Color Changes and Haze Development in Juice of "Merlot" and "Ruby" Grapes (Vitis vinifera). Front. Nutr. 2018, 5, 100. [CrossRef]

46. Waterhouse, G.I.N.; Sun-Waterhouse, D.; Su, G.; Zhao, H.; Zhao, M. Spray-Drying of Antioxidant-Rich Blueberry Waste Extracts; Interplay Between Waste Pretreatments and Spray-Drying Process. Food Bioprocess Technol. 2017, 10, 1074-1092. [CrossRef]

47. Silva-Espinoza, M.A.; Ayed, C.; Foster, T.; Camacho, M.D.M.; Martínez-Navarrete, N. The Impact of Freeze-Drying Conditions on the Physico-Chemical Properties and Bioactive Compounds of a Freeze-Dried Orange Puree. Foods 2019, 9, 32. [CrossRef]

48. Bouayed, J.; Hoffmann, L.; Bohn, T. Total phenolics, flavonoids, anthocyanins and antioxidant activity following simulated gastro-intestinal digestion and dialysis of apple varieties: Bioaccessibility and potential uptake. Food Chem. 2011, 128, 14-21. [CrossRef] [PubMed]

49. Del Rio, D.; Borges, G.; Crozier, A. Berry flavonoids and phenolics: Bioavailability and evidence of protective effects. Br. J. Nutr. 2010, 104, S67-S90. [CrossRef]

50. Çelik, E.E.; Gökmen, V.; Fogliano, V. Soluble Antioxidant Compounds Regenerate the Antioxidants Bound to Insoluble Parts of Foods. J. Agric. Food Chem. 2013, 61, 10329-10334. [CrossRef] [PubMed]

51. Masisi, K.; Beta, T.; Moghadasian, M.H. Antioxidant properties of diverse cereal grains: A review on in vitro and in vivo studies. Food Chem. 2016, 196, 90-97. [CrossRef]

52. Dulf, F.V.; Vodnar, D.C.; Dulf, E.-H.; Pintea, A. Phenolic compounds, flavonoids, lipids and antioxidant potential of apricot (Prunus armeniaca L.) pomace fermented by two filamentous fungal strains in solid state system. Chem. Cent. J. 2017, 11, 92. [CrossRef]

53. Hui, X.; Wu, G.; Han, D.; Gong, X.; Stipkovits, L.; Wu, X.; Tang, S.; Brennan, M.A.; Brennan, C.S. Bioactive compounds from blueberry and blackcurrant powder alter the physicochemical and hypoglycaemic properties of oat bran paste. LWT 2021, 111167. [CrossRef]

54. Gulcin, İ. Antioxidants and antioxidant methods: An updated overview. Arch. Toxicol. 2020, 94, 651-715. [CrossRef] [PubMed]

55. Cömert, E.D.; Gökmen, V. Antioxidants Bound to an Insoluble Food Matrix: Their Analysis, Regeneration Behavior, and Physiological Importance. Compr. Rev. Food Sci. Food Saf. 2017, 16, 382-399. [CrossRef] [PubMed]

56. Mittal, M.; Siddiqui, M.R.; Tran, K.; Reddy, S.P.; Malik, A.B. Reactive oxygen species in inflammation and tissue injury. Antioxid. Redox Signal. 2014, 20, 1126-1167. [CrossRef]

57. He, L.; He, T.; Farrar, S.; Ji, L.; Liu, T.; Ma, X. Antioxidants Maintain Cellular Redox Homeostasis by Elimination of Reactive Oxygen Species. Cell. Physiol. Biochem. 2017, 44, 532-553. [CrossRef]

58. He, F.; Ru, X.; Wen, T. NRF2, a Transcription Factor for Stress Response and Beyond. Int. J. Mol. Sci. 2020, 21, 4777. [CrossRef]

59. Kansanen, E.; Kuosmanen, S.M.; Leinonen, H.; Levonen, A.-L. The Keap1-Nrf2 pathway: Mechanisms of activation and dysregulation in cancer. Redox Biol. 2013, 1, 45-49. [CrossRef]

60. Tonelli, C.; Chio, I.I.C.; Tuveson, D.A. Transcriptional Regulation by Nrf2. Antioxid. Redox Signal. 2018, 29, 1727-1745. [CrossRef]

61. Mozaheb, N.; Arefian, E.; Amoozegar, M.A. Designing a whole cell bioreporter to show antioxidant activities of agents that work by promotion of the KEAP1-NRF2 signaling pathway. Sci. Rep. 2019, 9, 3248. [CrossRef]

62. Ahmed, S.M.U.; Luo, L.; Namani, A.; Wang, X.J.; Tang, X. Nrf2 signaling pathway: Pivotal roles in inflammation. BBA Mol. Basis Dis. 2017, 1863, 585-597. [CrossRef] 
63. Funes, S.C.; Rios, M.; Fernández-Fierro, A.; Covián, C.; Bueno, S.M.; Riedel, C.A.; Mackern-Oberti, J.P.; Kalergis, A.M. Naturally Derived Heme-Oxygenase 1 Inducers and Their Therapeutic Application to Immune-Mediated Diseases. Front. Immunol. 2020, 11, 1467. [CrossRef] [PubMed]

64. Kurutas, E.B. The importance of antioxidants which play the role in cellular response against oxidative/nitrosative stress: Current state. Nutr. J. 2016, 15, 71. [CrossRef] [PubMed]

65. Tan, B.L.; Norhaizan, M.E.; Liew, W.-P.-P.; Sulaiman Rahman, H. Antioxidant and Oxidative Stress: A Mutual Interplay in Age-Related Diseases. Front. Pharmacol. 2018, 9, 1162. [CrossRef] [PubMed] 